\title{
Terapias medicamentosas empregadas no tratamento da Covid-19 no Brasil: revisão bibliográfica narrativa
}

\author{
Drug therapies used in the treatment of Covid-19 in Brazil: narrative bibliographic review \\ Terapias con drogas utilizadas en el tratamiento del Covid-19 en Brasil: revisión bibliográfica \\ narrativa
}

Recebido: 25/09/2021 | Revisado: 02/10/2021 | Aceito: 07/10/2021 | Publicado: 10/10/2021

\author{
Paulo Rodrigo Lima Braz \\ ORCID: https://orcid.org/0000-0002-8277-8902 \\ Centro Universitário Maurício de Nassau, Brasil \\ E-mail: rodrigobraz.98@outlook.com \\ Maria Aurineide Barbosa da Silva Cardoso \\ ORCID: https://orcid.org/0000-0002-3160-5155 \\ Centro Universitário Maurício de Nassau, Brasil \\ E-mail: aurineide090592@gmail.com \\ Raphael Santos de Oliveira \\ ORCID: https://orcid.org/0000-0001-6567-2068 \\ Centro Universitário Maurício de Nassau, Brasil \\ E-mail: raphael.eslog@gmail.com \\ Emanuela Aquino da Silva \\ ORCID: https://orcid.org/0000-0001-9373-8570 \\ Centro Universitário Maurício de Nassau, Brasil \\ E-mail: manududaaquino@gmail.com \\ Manoel Ribeiro de Sales Neto \\ ORCID: https://orcid.org/0000-0002-3845-8485 \\ Universidade Federal do Ceará, Brasil \\ E-mail: manoelribeiron@yahoo.com.br \\ Cybelle Façanha Barreto Medeiros Linard \\ ORCID: https://orcid.org/0000-0001-7927-9320 \\ Centro Universitário Maurício de Nassau, Brasil \\ E-mail: cybellelinard@yahoo.com.br \\ Nadja Mara de Sousa Lopes \\ ORCID: https://orcid.org/0000-0002-6688-3534 \\ Centro Universitário Maurício de Nassau, Brasil \\ E-mail: professoranadjalopes@gmail.com
}

\begin{abstract}
Resumo
Objetivo: Apresentar um panorama sobre a fisiopatologia da Covid-19 e tratamentos medicamentosos utilizados no Brasil. Metodologia: Trata-se de uma revisão bibliográfica narrativa. Foram realizadas buscas em sites oficiais (Ministério da Saúde do Brasil; Butantan); bases de dados Cochrane, Google Scholar, Pubmed e Scielo e textos complementares. As buscas ocorreram entre fevereiro e junho de 2021 com os termos 'Covid-19', 'Coronavírus' 'Pandemia', 'Vacinas Covid-19', 'SARS-CoV-2' e 'Terapias medicamentosas Covid-19'. Foram inclusos textos em inglês, português e espanhol, publicados a partir de 2020 e excluídos textos que não se relacionavam à temática. Resultados: Azitromicina, corticosteroides, antirretrovirais e anticoagulantes exemplificam fármacos usados no tratamento de Covid-19, além de prevenção com vacinas. Conclusão: No período desta revisão notou-se o esforço da comunidade científica no reposicionamento de fármacos para tratar a doença, mas não foram encontradas evidências que comprovassem a efetividade de um tratamento específico. As vacinas tornam-se um grande aliado na prevenção da doença.
\end{abstract}

Palavras-chave: Covid-19; Doença pelo novo Coronavírus; Reposicionamento de medicamentos.

\footnotetext{
Abstract

Objective: To present an overview of the pathophysiology of Covid-19 and drug treatments used in Brazil. Methodology: This is a narrative bibliographic review. Searches were performed on official websites (Ministry of Health of Brazil; Butantan); Cochrane, Google Scholar, Pubmed and Scielo databases and supplementary texts. Searches took place between February and June 2021 under the terms 'Covid-19', 'Coronavirus' 'Pandemia', 'Covid-19 vaccines', 'SARS-CoV-2' and 'Covid-19 drug therapies'. Texts in English, Portuguese and Spanish, published from 2020, were included and texts that were not related to the theme were excluded. Results: Azithromycin, corticosteroids, antiretrovirals and anticoagulants exemplify drugs used in the treatment of Covid-19, in addition to
} 
prevention with vaccines. Conclusion: During the period of this review, the effort of the scientific community in the repositioning of drugs to treat the disease was noted, but no evidence was found to prove the effectiveness of a specific treatment. Vaccines become a great ally in preventing the disease.

Keywords: Covid-19; Disease 2019, Coronavirus; Drug repositioning.

\section{Resumen}

Objetivo: Presentar una visión general de la fisiopatología del Covid-19 y los tratamientos farmacológicos utilizados en Brasil. Metodología: Se trata de una revisión bibliográfica narrativa. Las búsquedas se realizaron en sitios web oficiales (Ministerio de Salud de Brasil; Butantan); Bases de datos Cochrane, Google Scholar, Pubmed y Scielo y textos complementarios. Las búsquedas se realizaron entre febrero y junio de 2021 bajo los términos 'Covid-19', 'Coronavirus', 'Pandemia', 'Vacunas Covid-19', 'SARS-CoV-2' y 'Terapias farmacológicas Covid-19'. Se incluyeron los textos en inglés, portugués y español, publicados a partir de 2020 y se excluyeron los textos que no estaban relacionados con el tema. Resultados: La azitromicina, los corticosteroides, los antirretrovirales y los anticoagulantes ejemplifican los fármacos utilizados en el tratamiento de Covid-19, además de la prevención con vacunas. Conclusión: Durante el período de esta revisión se notó el esfuerzo de la comunidad científica en el reposicionamiento de fármacos para tratar la enfermedad, pero no se encontró evidencia que demuestre la efectividad de un tratamiento específico. Las vacunas se convierten en un gran aliado para prevenir la enfermedad.

Palabras clave: Covid-19; Enfermedad 2019, Coronavirus; Reposicionamiento de fármacos.

\section{Introdução}

Covid-19 é a doença causada pelo novo coronavírus, o SARS-CoV-2, do gênero Betacoronavírus. Seu primeiro caso foi confirmado na China, em dezembro de 2019 e, em poucos meses, a infecção se propagou pelo mundo adoecendo mais de 100 milhões de indivíduos. Por sua abrangência geográfica e seu alto poder de disseminação, a Covid-19 colocou o mundo em estado de pandemia (Gorbalenya, et al, 2020). O vírus causador da doença possui relação com outros coronavírus que circulam entre os morcegos, sendo considerados o reservatório natural mais provável, porém com chance de haver um hospedeiro intermediário, ainda não foi identificado. Acredita-se que a propagação tenha começado em um mercado que comercializava animais vivos, na cidade de Wuhan (Gorbalenya, et al, 2020).

No momento da descoberta da doença, os cientistas chineses a descreviam como uma infecção com comportamento similar ao da gripe comum, pois a maioria dos doentes apresentavam sintomas cuja remissão se dava entre 14 e 21 dias. Foi observado também que pessoas com diferentes comorbidades e sobretudo idosos eram mais vulneráveis à infecção pelo novo coronavírus (Maltez, 2020). Medidas sanitárias começaram a ser empregadas na tentativa de conter a disseminação, entretanto o patógeno possuía características que o tornavam mais difícil de controlar.

A doença é transmitida sobretudo através de gotículas respiratórias, expelidas transversalmente pela tosse ou espirro, durante o contato próximo entre pessoas, além do contato direto com gotículas e superfícies contaminadas. Ademais, a Covid19 pode se propagar através de pessoas sintomáticas e assintomáticas, com o período de incubação variando em torno de cinco dias. Os sintomas mais comuns são febre, tosse seca e falta de ar (Organização Pan-Americana da Saúde, 2020).

Por ter uma rápida velocidade de transmissão e consequentemente uma alta taxa de mortalidade, o SARS-CoV-2 desafiou a comunidade científica a se empenhar na busca por tratamentos capazes de controlar a doença. Nesse intuito, uma alternativa rápida e possível para a atual situação é o reposicionamento de fármacos, processo que, segundo Ferreira e Andricopulo (2020), procura identificar novas designações para medicamentos aprovados ou que estão em fases clínicas avançadas através de triagens fenotípicas, seguidas de ensaios clínicos de fases 2 e 3.

Esse método inovador tem contribuído bastante para tratamento e controle de várias patogenias. Em contrapartida, a recolocação de fármacos para tratar doenças secundárias possui algumas limitações associadas à sua condição de tentativa e erro (Ferreira, Andricopulo, 2020).

De dezembro de 2019 até os dias atuais, vários estudos vêm sendo realizados e dedicados à busca de possibilidades terapêuticas para o tratamento da Covid-19, como os que avaliaram antivirais, antibióticos como a azitromicina, corticosteroides, além dos anticoagulantes. 
A ciência é a principal arma para combater a Covid-19 e tem proporcionado esperança e otimismo para o mundo. Mesmo quando se sabia pouco sobre o vírus, ela permitiu seguir algumas linhas de tratamentos medicamentosos ao qual foi possível atenuar os efeitos do vírus sobre o corpo humano (Ministério da Saúde, 2020). Esta revisão bibliográfica tem como objetivo apresentar um panorama sobre a fisiopatologia da Covid-19 e os tratamentos medicamentosos utilizados para o enfrentamento dessa doença no Brasil.

\section{Metodologia}

Trata-se de uma revisão bibliográfica narrativa. Neste tipo revisão descreve-se ou discute-se sobre algum assunto do ponto de vista teórico ou contextual, seguindo-se a interpretação e análise crítica pessoal do(s) autor(es). Este tipo de artigo permite que se desenvolva educação continuada sobre um tema específico em curto espaço de tempo, apesar de não permitir a reprodução dos dados obtidos (Rother, 2007). Para a sua construção foram realizadas buscas em sites oficiais, como os do Ministério da Saúde do Brasil e do Instituto Butantan; nas bases de dados Cochrane Library, Google Scholar, National Library of Medicine (PUBMED) e Scientific Eletronic Library Online (SCIELO); em sites não oficiais, tais como Agência Brasil e do laboratório PFIZER. Esses últimos foram inclusos para complementar informações acerca do mecanismo de ação das vacinas, bem como suas datas de aprovação pela ANVISA. As buscas ocorreram no período de fevereiro a junho de 2021 usando como palavras-chave: 'Covid-19', 'Coronavírus' 'Pandemia', 'Vacinas Covid-19', 'SARS-CoV-2' e 'Terapias medicamentosas Covid-19'. Foram inclusos textos em inglês, português e espanhol, publicados a partir de 2020 e excluídos textos repetidos ou que não se relacionavam à temática.

\section{Resultados e Discussão}

No total, foram selecionados 18 artigos para descrição dos resultados, visando apresentar a fisiopatologia da Covid19, assim como sua patogenicidade e tratamentos medicamentosos que foram e que vêm sendo utilizados no Brasil no atual momento.

\section{Estrutura e Patogenicidade do SARS-CoV-2}

O SARS-CoV-2 é um novo coronavírus de RNA formado por cerca de 29 proteínas distintas onde se destacam algumas, entre elas a proteína $(\mathrm{N})$, encontrada no nucleocapsídeo viral (envoltura que protege o material genético) inserida na bicamada fosfolipídica, localizada na membrana externa, que ordena a reprodução do material genético viral (Uzunian, 2020). Na membrana externa do vírus, também estão localizadas proteínas consideradas estruturais, como as proteínas Spike (S), de membrana (M), de envoltura (E) e uma acessória, denominada de hemaglutinina esterase (HE). A proteína (S) favorece a ligação do vírus ao receptor da célula que será infectada; a proteína $\mathrm{M}$ ajuda a manter a união com o nucleocapsídeo, a proteína E participa da liberação do vírus e a proteína $\mathrm{N}$ contribui para a ligação do material viral à célula hospedeira. A proteína assessória HE, que está presente em alguns Betacoronavírus, facilita a entrada do vírus na célula, contribuindo para a formação de um vírus com um maior poder de propagação (Pastrian-Soto, 2020).

Para infectar a célula hospedeira, a proteína ( $\mathrm{S}$ ) do patógeno se acopla ao receptor da enzima conversora de angiotensina 2 (ACE2) que se localiza na superfície celular. Vale ressaltar que ACE2 participa da regulação da pressão arterial convertendo angiotensina I em angiotensina II e está presente no pulmão, no rim, no coração, na bexiga, no estômago, no esôfago e no intestino (Pastrian-Soto, 2020). Após a interação do microrganismo com o receptor ACE2, a membrana lipídica do vírus permeia a membrana celular e adentra a célula. Em seguida, um compartimento membranoso chamado de endossomo é formado proveniente da fusão das membranas viral e celular. No interior do endossomo o vírus é aprisionado e replicado, produzindo fitas de RNA+ que posteriormente serão liberadas para a produção de proteínas virais (Uzunian, 2020). 
Pesquisadores do Instituto Oswaldo Cruz (IOC/Fiocruz) observaram, através de microscopia de alta resolução, que células infectadas expressam prolongamentos de membrana, denominados de filopódios, com a função de formar conexões intercelulares, o que pode ampliar a capacidade de infecção (Fiocruz, 2020).

\section{Reposicionamento de fármacos}

A fim de buscar um tratamento eficaz e rápido para minimizar os transtornos causados pela pandemia de COVID-19, o reposicionamento de fármacos é uma alternativa, pois tem um tempo e um custo de desenvolvimento menor em relação ao processo tradicional de pesquisa e desenvolvimento (Ferreira, Andricopulo, 2020).

É importante salientar que a maioria dos estudos são fundamentados na interação bioquímica onde a droga em questão se liga a um alvo molecular específico, o que explica, de forma teórica, o mecanismo de ação dos fármacos no organismo (Ferreira, Andricopulo, 2020).

Mesmo não havendo nenhum estudo que comprove a eficácia de algum medicamento que seja competente para o controle introdutório da doença, algumas drogas foram e ainda estão sendo usadas para amenizar a sintomatologia e minimizar os efeitos que o vírus causa no corpo quando infectado (Ferreira, Andricopulo, 2020). A seguir, seguem alguns exemplos desses medicamentos.

\section{a) Azitromicina e associação a Cloroquina/Hidroxicloroquina}

A azitromicina atua inibindo a síntese proteica, ligando-se ao sítio 23S do RNAr da subunidade 50S, causando uma interferência nas reações de peptidação e translocação (Iriarte, 2020).

Autoridades de saúde de vários países recomendaram o uso em associação de hidroxicloroquina/cloroquina e azitromicina para o tratamento de Covid-19, com base em estudos preliminares, tendo como objetivo prevenir ou tratar a infecção respiratória aguda (Stein, et al, 2020).

Segundo Rosenberg et al. (2020), em um estudo de coorte retrospectivo realizado em Nova Iorque, não houve diferenças significativas na mortalidade intra-hospitalar entre os pacientes que receberam hidroxicloroquina (HCQ) com azitromicina e os pacientes que não receberam nenhum dos medicamentos. Observou-se também que nos pacientes que receberam azitromicina mais hidroxicloroquina (HCQ), a parada cardíaca foi mais frequente em relação aos pacientes que não receberam nenhum dos medicamentos.

Ainda de acordo com Falavigna et al. (2020), o painel de recomendações entendeu que as evidências disponíveis não sugerem benefício clinicamente significativo do tratamento com HCQ ou com CQ em associação com azitromicina. Mas houve entendimento de que o risco de eventos adversos cardiovasculares é moderado, em especial de arritmias, sendo potencializados com a associação de HCQ/CQ com azitromicina, necessitando maiores cuidados em relação a esses eventos adversos.

Em informe publicado no dia 17 de setembro de 2020, a Sociedade Brasileira de Infectologia (SBI) recomendou que a hidroxicloroquina fosse abandonada no tratamento de qualquer fase da Covid-19, baseando-se em dois estudos clínicos. Um dos estudos avaliou pacientes com Covid-19 em 40 estados americanos e 3 províncias do Canadá e observou-se que não houve qualquer benefício clínico dentre os pacientes que receberam hidroxicloroquina em relação aos pacientes que receberam placebo. O outro estudo, realizado na Espanha avaliou a eficácia virológica e clínica e observou-se que nenhum benefício virológico, nem clínico, foi observado em relação aos pacientes que não receberam nenhum tratamento farmacológico (Sociedade Brasileira de Infectologia, 2020).

Já em nota de esclarecimento publicada em 25 de maio de 2021, a SBI (Sociedade Brasileira de Infectologia), reconheceu a ineficácia dos medicamentos cloroquina e ivermectina no tratamento da Covid-19, levando em consideração os 
níveis de evidência que tiveram reconhecimento da comunidade científica, como ensaios clínicos randomizados, duplo-cegos, e que guiaram as recomendações das principais sociedades médica e instituições pelo mundo, tal como, Organização Mundial da Saúde (OMS), Sociedade Norte-Americana de Doenças Infecciosas (IDSA), Instituto Nacional de Saúde dos Estados Unidos (NIH), Sistema Nacional de Saúde do Reino Unido (NHS) e Sociedade Europeia de Microbiologia Clínica e Doenças Infecciosa (ESCMID) (Sociedade Brasileira de Infectologia, 2021).

\section{b) Corticosteroides}

Segundo Drumond et al. (2021), os anti-inflamatórios esteroidais (AIEs) ou corticosteroides, se ligam a receptores intracelulares específicos onde provocam a inibição do sistema imunológico inato e adaptativo. Eles atuam diminuindo a ativação de células do sistema imune como os neutrófilos, macrófagos e mastócitos. Os corticosteroides também reduzem a transcrição genética de elementos de contribuem para adesão celular e produção de citocinas, além de limitarem a ativação de células T Helper (Th), aumentando a síntese de fatores anti-inflamatórios, especialmente IL-10, receptor solúvel de IL-1 e anexina-1. Em indivíduos acometidos pela Covid-19, o uso de corticosteroides tem o objetivo de reduzir a liberação de citocinas pró-inflamatórias diminuindo assim, a forte expressão de interleucinas (Drumond, et al, 2021). De acordo com Ministério da Saúde - MDS (2020), a utilização de corticosteroides ainda é discutível. Estudos demostraram que para a influenza e para MERS-CoV, outro tipo de coronavírus, a utilização de corticosteroides pareceu ser danosa ao organismo (Drumond, et al, 2021). Um estudo caso-controle que foi executado com 309 adultos infectados com o vírus MERS-CoV, em 151 pacientes que receberam corticoides, foi observado uma maior necessidade de ventilação mecânica, vasopressores e terapia de substituição renal. Observou-se também que a administração de corticosteroides não resultou em diferença de mortalidade em 90 dias, mas estava relacionada à excreção prolongada de RNA viral nas secreções do trato respiratório (Drumond, et al, 2021).

c) Lopinavir em associação ao Ritonavir

A terapêutica antirretroviral (TARV) é a terapia medicamentosa utilizada para o tratamento do vírus da imunodeficiência humana (HIV), e o Lopinavir (LPV) e o Ritonavir (RTV) se encontram entre esses fármacos. Essas drogas atuam inibindo a enzima protease, impedindo o amadurecimento das moléculas virais por meio da modificação do processo de corte de enzimas e proteínas estruturais do capsídeo viral que está se formando, produzindo, assim, vírions sem capacidade infectante (Duarte, Coelho, Nascimento, 2020). Sabe-se que as enzimas hepáticas CYP3A4 e CYP3A5 metabolizam o LPV quando administradas isoladamente, entretanto o fármaco não atinge a concentração plasmática adequada para impedir a replicação do vírus HIV. Para auxiliar no desempenho do LPV, é administrado conjuntamente, em doses baixas, o fármaco RTV, que irá inibir as enzimas hepáticas garantindo que o LPV atinja altas concentrações, impedindo a replicação viral. Baseados nesse mecanismo, estudiosos levantaram a hipótese que esses fármacos poderiam ter ação sobre o vírus SARS-CoV2. Em um estudo clínico controlado, aberto e randomizado, conduzido por Cao et al (2020), foram realizados em pacientes adultos confirmados para Covid-19, no qual a terapia farmacológica LPV/r (Lopinavir + Ritonavir) foi implantada, com a dosagem de 400 e 100mg duas vezes ao dia durante 14 dias, mais tratamento padrão para o grupo experimental e apenas o tratamento padrão para o grupo controle. Esses estudos demostraram que não houve diferenças significativas entre os grupos, indicando, assim, que não há benefício no uso de LPV/r para o tratamento do SARS-CoV-2.

\section{d) Remdesivir}

O Remdesivir é um medicamento antiviral de amplo espectro, que durante a pandemia do Covid-19, foi muito citado e utilizado como opção de tratamento. Originalmente criado para tratar o vírus Ebola, o medicamento também demonstrou 
atividade contra vírus de RNA em várias famílias, incluindo Coronaviridae (como por exemplo: SARS-CoV-2). Dado que é um análogo de nucleosídio, o Remdesivir atua como inibidor do RNA polimerase, visando interromper o processo de replicação do genoma viral, resultando em um término prematuro da síntese de RNA. Apesar dos vírus deste gênero serem capazes de reconhecer e remover outros análogos de nucleosídios, tornando-se assim resistentes a medicamentos desta classe, o Remdesivir demonstrou até o momento ser eficaz no processo de diminuição da replicação viral. É relevante citar que o primeiro paciente a ser diagnosticado com Covid-19 nos Estados Unidos (EUA) foi tratado com Remdesivir, o mesmo ficou hospitalizado por 12 dias e a partir do $7^{\circ}$ dia iniciou o tratamento com o fármaco, no dia seguinte apresentou melhora significativa em sua condição, e, além disso, não apresentou nenhum efeito adverso (Amirian, Levy, 2020).

Diante deste cenário, o fármaco apresentou resultados esperançosos e recebeu, em maio de 2020, a aprovação do Food and Drug Administration (FDA) para uso emergencial em pacientes graves com Covid-19 (Ferreira, Andricopulo, 2020). No entanto os estudos mais relevantes sobre este assunto utilizaram vírus com a genética idêntica ao da pandemia atual, porém atualmente existe uma quantidade enorme de mutações e variações nas cepas que se encontram ativas, e apesar dos esforços da comunidade científica em comprovar que algum tratamento seja de fato eficiente contra a doença, ainda não é seguro afirmar que, apesar do fármaco Remdesivir ser de amplo espectro, será útil para a SARS-CoV-2, assim como é para outros gêneros de vírus semelhantes (Amirian, Levy, 2020).

\section{e) Anticoagulantes}

A terapia anticoagulante em pacientes com Covid-19 grave, que têm, em dosagem alta, um produto da degradação da fibrina que é usado para medir e avaliar a formação do coágulo (dímero-D), em associação a outros biomarcadores na ausência de contraindicação à anticoagulação, pode ser considerada uma estratégia terapêutica para auxiliar o tratamento da infecção causada pelo vírus SARS-CoV-2. De acordo com critérios estabelecidos pela Sociedade Internacional de Trombose e Hemostasia (ISTH), o uso de anticoagulantes, principalmente em pacientes cujo estado é considerado crítico, pode estar relacionado a complicações hemorrágicas graves. Diante disso, essa estratégia requer a utilização de protocolos institucionais rígidos que permitam a vigilância e a rápida intervenção frente a complicações. Embora ainda não exista uma comprovação científica sobre o uso dos anticoagulantes para tratar pacientes com Covid-19 em estado crítico, há indícios de que uma terapêutica anticoagulante seja mais benéfica quando iniciada na fase pré-trombótica do que nos quadros avançados, quando o risco de sangramento é maior. Sendo assim, seria aconselhável o uso de Heparina de baixo peso molecular (HBPM) como fármaco de escolha em pacientes estáveis e com depuração normal de creatinina (dose de $1 \mathrm{mg} / \mathrm{kg}$ de 12/12h, subcutânea). Em caso de choque ou depuração de creatinina abaixo de $50 \mathrm{ml} / \mathrm{min} / \mathrm{m}^{2}$, é preferível o uso de heparina intravenosa (18 UI/ $\left./ \mathrm{kg} / \mathrm{h}\right)$, tendo como alvo um tempo de tromboplastina parcial ativada entre 1,5 e 1,8. Porém é importante salientar que não há evidências que baseiem a excessiva utilização de heparina em dose terapêutica na Covid-19. (Ministério da Saúde, 2020).

\section{Perspectivas de tratamento imunobiológico}

Uma perspectiva promissora de prevenção à Covid-19 são as vacinas que, por sua vez, seguem uma ordem de fases no seu processo de produção, fase de estudo clínico, com etapas pré-clínicas, sendo realizadas em laboratórios, modelos animais, com o objetivo de avaliar a dose e a toxicidade. Os ensaios clínicos em humanos são divididos em três etapas, fases 1, 2 e 3 . $\mathrm{Na}$ fase 1, avalia-se a segurança do produto, na fase 2, segurança, dose e frequência de administração e sua imunogenicidade (Lima, et al, 2021). Já na fase 3, avalia-se a eficácia do produto, por meio de ensaios clínicos controlados e randomizados, em uma amostra da população voluntária. Após a obtenção dos dados, a vacina é submetida à avaliação pelos órgãos reguladores, autorizando sua produção e distribuição. Nos estudos de fase 4, observam-se os possíveis efeitos e eventos adversos após a utilização da vacina em larga escala imunogenicidade (Lima, et al, 2021) 
De acordo com o Instituto Butantan (2021), dentre as vacinas utilizadas no Brasil estão a CoronaVac, anunciada oficialmente pelo Instituto Butantan no dia 12 de janeiro de 2021, que promove uma reação de sensibilização no organismo estimulando a produção de célula $\mathrm{T}$, utilizando uma versão do vírus inativado sem que haja reações do patógeno original.

No dia 12 de março 2021 a ANVISA concedeu o registro da vacina ChAdOx1 nCoV-19 do laboratório AstraZeneca, que utiliza, como vetor, um adenovírus não replicante de chimpanzé que, por sua vez, expressa a proteína S (Spike) do SarsCov-2 (Lima, et al, 2021)

Autorizada no dia 23 de fevereiro de 2021, a vacina do laboratório Pfizer enfrentava no Brasil um grande desafio referente ao armazenamento, devido à necessidade de ser mantida de $-90^{\circ} \mathrm{C}$ a $-60^{\circ} \mathrm{C}$ com durabilidade de 6 meses, porém estudos de estabilidade apresentados comprovam que a vacina mantém suas características quando armazenadas entre $2^{\circ} \mathrm{C}$ e $8^{\circ} \mathrm{C}$ por até cinco dias e armazenadas e transportadas fechadas entre $-25^{\circ} \mathrm{C} \mathrm{e}-15^{\circ} \mathrm{C}$ por período único de duas semanas, podendo retornar a $-90^{\circ} \mathrm{C}$ a $-60^{\circ} \mathrm{C}$ (Ministério da Saúde, 2021).

A vacina age por meio do RNA mensageiro, o qual se utiliza um fragmento sintético do código genético do vírus que, quando administrado, não é capaz de causar infecção, contudo é suficiente para produzir uma resposta imune (Pfizer; Reis, Leite, Costa, 2021).

Além das vacinas, uma outra perspectiva promissora autorizada pela ANVISA, para uso em caráter emergencial, foi anunciada no dia 13 de maio de 2021, que é o novo coquetel para o tratamento de pacientes com COVID-19. Ele é baseado no uso combinado dos medicamentos Banlanivimabe e Etesevimabe, da empresa Eli Lilly, e são de anticorpos monoclonais que têm como objetivo a neutralização do vírus antes que adentre a célula (Agência Brasil, 2021).

\section{Considerações Finais}

A leitura aprofundada dos textos permitiu a descrição da fisiopatologia da infecção causada pelo SARS-CoV-2 e o reposicionamento de fármacos para seu possível tratamento. Embora tenha havido um grande esforço por parte da comunidade científica na tentativa de reposicionar fármacos com o objetivo de tratar ou frear as ações do vírus no organismo humano, ainda não existem evidências científicas que comprovem efetividade de um tratamento medicamentoso específico para infecção causada pelo Sars-CoV-2, evidenciando a necessidade de mais estudos nesse contexto. Logo, as vacinas tornam-se uma grande esperança no que se diz respeito a prevenção da Covid-19, o que possibilitaria um retorno à normalidade.

Perante o exposto, fica claro a imprescindibilidade da realização de mais pesquisas clínicas acerca da fisiopatologia da doença, do comportamento viral e principalmente, em relação aos tratamentos utilizados. Ressaltamos a importância do investimento em estudos que possibilitem o desenvolvimento de novas opções farmacoterapêuticas, a fim de garantir um tratamento seguro e eficaz contra a Covid-19.

\section{Referências}

Agência Brasil. (2021). Anvisa autoriza uso emergencial de coquetel contra a covid-19. Publicado em 13/05/2021 por Jonas Valente - Repórter Agência Brasil. https://agenciabrasil.ebc.com.br/saude/noticia/2021-05/anvisa-autoriza-uso-emergencial-de-coquetel-para-covid-19.

Amirian, E. S., \& Levy, J. K. (2020). Current knowledge about the antivirals remdesivir (GS-5734) and GS-441524 as therapeutic options for coronaviruses. One Health, v. 9.

Cao, B., Wang, Y., Wen, D., et al. (2020). A trial of lopinavir-ritonavir in adults hospitalized with severe Covid-19. The New England Journal of Medicine. v. $382(19), 1789-1799$.

Drumond, L. M., Coelho, T. P., Santos, R. M., Cordeiro, J. M. G., Alves, C. G., Neves, C. O. Rocha, V. M. C., \& Moura, A. S. (2021). O uso dos corticosteroides e do tocilizumabe no tratamento da covid-19: revisão da literatura. Revista Conexão Ciência I. v. 16.

Duarte, D. B., Coelho, L. J., \& Nascimento, G. L. (2020). Atualidades da farmacoterapia da COVID-19. Desafios - Revista Interdisciplinar da Universidade Federal do Tocantins. v. 7, 81-89.

Falavigna, M., Colpani, V., Stein, C., et al. (2020). Diretrizes para o tratamento farmacológico da COVID-19. Rev. bras. ter. intensiva. v. 32(2), 166-196. 
Ferreira, L. G., \& Andicopulo, A. D. (2020). Medicamentos e tratamentos para a Covid-19. Estudos Avançados [online]. V. 34(100), 7-27.

Fiocruz. (2020). Fiocruz e Inmetro registram imagens do coronavirus em ação. Agência Fiocruz de Notícias. Publicado em 01/10/2020 por Maíra Menezes. https://agencia.fiocruz.br/fiocruz-e-inmetro-registram-imagens-do-coronavirus-em-acao.

Gorbalenya, A. E., Baker, S. C., Baric, R., et al. (2020). Severe acute respiratory syndrome-related coronavirus: The species and its viruses-a statement of the Coronavirus Study Group.

Iriarte D. A. (2020). Resistência bacteriana aos Macrolídeos: um olhar sobre a Azitromicina. Repositório Institucional UFSCar.

Lana, R. M., Coelho, F. C., \& Gomes, M. d. C. (2020). Emergência do novo coronavírus (SARS-CoV-2) e o papel de uma vigilância nacional em saúde oportuna e efetiva. Cadernos Saúde Pública. v.36.

Lima, D. L. F., Dias, A. A., \& Rabelo, R. S., et al. (2020). COVID-19 no estado do Ceará, Brasil: comportamentos e crenças na chegada da pandemia. Ciência \& Saúde Coletiva [online]. V.25(5), 1575-1586.

Lima, E. J. D. F., Almeida, A. M., \& Kfouri, R. D. Á. (2021). Vacinas para COVID-19-o estado da arte. Revista Brasileira de Saúde Materno Infantil, v.21, $13-19$.

Maltez, F. (2020). COVID-19: A Segunda Pandemia do Século XXI. Medicina Interna. 27, 53-54.

Ministério da Saúde (2020). Diretrizes para diagnóstico e tratamento da covid-19. https://portaldeboaspraticas.iff.fiocruz.br/wpcontent/uploads/2020/05/Diretriz-Covid19-v4.pdf

Ministério da Saúde. (2021). Anvisa aprova registro da vacina da Fiocruz/AstraZeneca e de medicamento contra o coronavírus. https://www.gov.br/anvisa/ptbr/assuntos/noticias-anvisa/2021/anvisa-aprova-registrodavacinadafiocruzastrazenecaedemedicamentocontracoronavirus\#: :text=COVID\%2D19,Anvis a\% $20 \mathrm{apr}$ ova\%20re gistro\%20da\%20vacina\%20da\%20Fiocruz\%2FAstraZeneca \%20e\%20de,ser\%20usados\%20amplamente \%20no\%20pa\%C3\%ADs.\&text=A \%20popula\%C3\%A7\%C3\%A3o\%20brasileira\%20passa\%20a,luta\%20contra\%20o\%20novo\%20coronav\%C3\%ADrus

Ministério da Saúde (2021). Anvisa atualiza condições de armazenamento da vacina da Pfizer. https://www.gov.br/anvisa/pt-br/assuntos/noticiasanvisa/2021/anvisa-atualiza-condicoes-de-armazenamento-da-vacina-da-pfizer.

Nascimento, J. H. P., Gomes, B. F. D. O., Carmo, P. R., et al, (2020). COVID-19 e estado de hipercoagulabilidade: uma nova perspectiva terapêutica. Arquivos Brasileiros de Cardiologia. v.114, 829-833.

Organização Pan-Americana da Saúde (2020). Transmissão do SARS-CoV-2: implicações para as precauções de prevenção de infecção. https://iris.paho.org/bitstream/handle/10665.2/52472/OPASWBRACOVID1920089_por.pdf?sequence=1\&isAllowed=y\#: :text=As\%20evid\%C3\%AAncias\% 20atuais $\% 20$ sugerem $\% 20$ que $\% 20 \mathrm{a} \% 20$ transmiss $\% \mathrm{C} 3 \% \mathrm{~A} 3 \mathrm{o} \% 20 \mathrm{do} \% 20 \mathrm{SARS} \% 2 \mathrm{DCoV}, \mathrm{s} \% \mathrm{C} 3 \% \mathrm{~A} 3 \mathrm{o} \% 20$ expelidas\%20quando $\% 20$ uma $\% 20 \mathrm{pessoa}$.

Pastrian-Soto, G. (2020). Bases genéticas y moleculares del COVID-19 (SARS-CoV-2). Mecanismos de patogénesis y de respuesta inmune. International journal of odontostomatology. v.14(3), 331-337.

Pfizer. (2021). COVID-19- Principais perguntas \& respostas sobre vacina pfizer e biontech. https://www.pfizer.com.br/sua-saude/covid-19-coronavirus/covid19-principaisperguntas-respostas-sobre-vacina-pfizer-e-biontech.

Reis, R. P., Leite, J. G. R., \& Costa, G. A. (2021). Vacinas contra Covid-19: o que podemos dizer nesse momento. n. 14.

Rosenberg, E. S., Dufort, E. M., Udo, T., Wilberschied, L. A., et al. (2020). Association of treatment with hydroxychloroquine or azithromycin with inhospital mortality in patients with COVID-19 in New York State. Jama. v.323(24), 2493-2502.

Rother, E. T. Revisão sistemática X revisão narrativa. (2007). Acta paul.enferm. v.20(2).

Sociedade Brasileira de Infectologia. (2020). Informe $\mathrm{N}^{\circ} 16$ Sobre: Atualização sobre hidroxicloroquina no tratamento precoce da covid-19. https://infectologia.org.br/2020/07/17/atualizacao-sobre-a-hidroxicloroquina-no-tratamento-precoce-da-covid-19.

Sociedade Brasileira de Infectologia. (2021). Nota de Esclarecimento. http://infectologia.org.br/2021/05/25/nota-de-esclarecimento/

Stein C., Falavigna, M., Marcolino, M. A. Z., et al. (2020). Associação hidroxicloroquina/cloroquina e azitromicina para Covid-19. Revisão sistemática rápida. https://oxfordbrazilebm.com/index.php/2020/06/02/associacao-hidroxicloroquina-cloroquina-eazitromicina-para-covid-19-revisao-sistematica-rapida

Uzunian, A. (2020). Coronavírus SARS-CoV-2 e Covid-19. Jornal Brasileiro de Patologia e Medicina Laboratorial [online]. v. 56. 